\title{
Role of Tropical Convective Cells in the Observed Middle Atmospheric Gravity Wave Properties from Two Distant Low Latitude Stations
}

\author{
A. Taori \\ National Atmospheric Research Laboratory, Gadanki- 517112, India \\ Tel: 91-838-520-2024Ｅ-mail: alok.taori@gmail.com \\ S. Raizada \\ Arecibo Observatory, HC-03, Arecibo, Puerto Rico - 00612, USA \\ M. Venkat Ratnam \\ National Atmospheric Research Laboratory, Gadanki- 517112 India \\ C. A. Tepley \\ Arecibo Observatory, HC-03, Arecibo, Puerto Rico - 00612, USA \\ D. Nath \& A. Jayaraman \\ National Atmospheric Research Laboratory, Gadanki- 517112, India
}

Received: August 22, 2011 Accepted: September 13, $2011 \quad$ Published: February 1, 2012

doi:10.5539/esr.v1n1p87 URL: http://dx.doi.org/10.5539/esr.v1n1p87

\begin{abstract}
We investigate the role of convective processes in triggering middle atmospheric gravity waves with the help of simultaneous measurements of middle atmospheric temperature variability from two tropical stations, Gadanki $\left(13.5^{\circ} \mathrm{N}, 79.2^{\circ} \mathrm{E}\right)$ and Arecibo $\left(18.3^{\circ} \mathrm{N}, 66.7^{\circ} \mathrm{W}\right)$. Our data reveal that some of the wave periods are similar at both locations indicating the source regions of waves to be similar at both the stations. However, the potential energies of short period gravity waves are found to be significantly higher over Gadanki compared to that at Arecibo. The most striking observation is that background wind conditions were similar and convective processes occurred very close to Gadanki compared to Arecibo. In the view absence of other wave sources during the period of observations, we suggest the strength as well as the distance of convective cells from the location of the observations is responsible for the observed differences in gravity wave spectrum and energies.
\end{abstract}

Keywords: Gravity wave, Thermal structure, Middle atmosphere, Convection, ITCZ

\section{Introduction}

Gravity waves have an important role in determining the middle atmospheric thermo-dynamical processes over short time scales. These waves also modify the background mean structure. Most of these waves are believed to originate at tropospheric altitudes (e.g., Fritts and Alexander, 2003 and references therein). They propagate to higher altitudes with growing amplitude to conserve their energy owing to the negative density gradient with increasing height. There are growing consensus that tropospheric convective activity is the prime source of short period gravity waves that are often observed in the mesosphere and lower thermospheric regions (e.g., Lane et al., 2003; Wrass et al., 2006; Vadas et al., 2009). It is also understood that inter-tropical convergence zone (ITCZ), which is dominated by such deep convective clouds will also be a source region of gravity wave generation (e.g., Espy and Huppi, 1997). 
Previous studies using MF radar located at Arecibo and Hawaii were used to study the longitudinal variability in lower mesospheric winds at these two locations (Zhou et al., 2000). In this report we examine the middle atmospheric variability from two distant low latitude stations, one located in the Indian sector and other located in the North American sector, to reveal the similarities and differences in the gravity wave characteristics for the first time. Interestingly, the position of the Inter Tropical Convergence Zone (ITCZ) during the period under consideration was such that one station, Gadanki $\left(13.5^{\circ} \mathrm{N}, 79.2^{\circ} \mathrm{E}\right)$ was situated very close to a deep convective pattern while other station, Arecibo $\left(18.3^{\circ} \mathrm{N}, 66.7^{\circ} \mathrm{W}\right)$ was somewhat far from the ITCZ. This can be noted clearly in Figure 1, which shows the daily mean NOAA interpolated outgoing long-wave radiation (OLR) data observed during 7-10 December 2009, which is considered as a proxy for the tropical deep convection (low OLR indicates the occurrence of a deep convection). Note that Gadanki is near the deep convective patches (located near to $8.1^{\circ} \mathrm{N}, 82.5^{\circ} \mathrm{E}$ ) on all the days, whereas Arecibo is located far away from the convective sources (located at $6.5^{\circ} \mathrm{N}, 30^{\circ} \mathrm{W}$ ). We believe that this unique study provides important insight on the role of convective activity in the generation and propagation of gravity waves and the energy associated with the triggered waves at middle atmospheric altitudes, which are not yet well explored.

\section{Instrument Description}

The middle atmospheric temperature measurements at Gadanki and Arecibo were carried out with the help of lidars using Rayleigh technique (Chanin and Hauchecorne, 1984). The following is a brief description of these lidar systems.

The Rayleigh lidar located at Gadanki employs a Nd: YAG laser with a maximum energy of $600 \mathrm{~mJ}$ per pulse at $532 \mathrm{~nm}$ with a pulse repetition frequency of $50 \mathrm{~Hz}$ and a pulse width of $7 \mathrm{~ns}$. A flat mirror oriented at $45^{\circ}$ to the beam axis directs the transmitted beam vertically with a divergence of $0.1 \mathrm{mrad}$. The receiver employs a Newtonian telescope with a primary mirror diameter of $75 \mathrm{~cm}$ for molecular density/temperature measurements over the height region of 30-80 km. A narrow band interference filter with full-width at half-maximum (FWHM) of $1.07 \mathrm{~nm}$ is used for wavelength selection. The signal is then split into two channels in the ratio of 9:1; the high gain channel (R) covers 50-80 km where the signal is weak and the low gain channel (U) covers $30-50 \mathrm{~km}$ where the signal is relatively strong. The signals are directed to photomultiplier tubes (Hamamatsu - R3234), and then fed to pulse discriminators, which, in turn, feed to a PC based photon-counting system. It operates with a real-time multichannel scalar (MCS) software that provides a photon count profile with a range resolution of 300 $\mathrm{m}$. The signal returns are integrated over 5000 laser shots, generating photon count profiles with a time resolution of $250 \mathrm{~s}$. The method of analysis adopted to determine the temperature profile closely follows that given by Hauchecorne and Chanin (1980). The accuracy of the temperature measurements varies between 0.5-1.5 K in the stratosphere and 2-3 K in the mesosphere (e.g., Sivakumar et al., 2006). Some of the results on mean thermal structure derived using the Rayleigh lidar observations have been reported elsewhere (e.g., Sharma et al., 2006) with more details about the instrument and data analysis.

The lidar system at Arecibo consists of a Nd:YAG laser as a transmitter, which pumps a dye laser at $532 \mathrm{~nm}$ and $50 \mathrm{~Hz}$ repetition rate. The average power at $532 \mathrm{~nm}$ is 30 Watts. This instrument is mainly used for resonance measurements of different mesospheric metals (Tepley et al., 2003, Raizada et al., 2004, Raizada et al., 2011). Such observations are obtained by tuning the transmitter wavelength to a specific resonance wavelength of a metal to be studied. For UV wavelengths, this is achieved by a non-linear sum-frequency mixing of the dye fundamental with the residual IR from the Nd:YAG. One of the advantages of this setup is that in addition to densities of mesospheric metals, one also receives molecular Rayleigh signal from strato-mesospheric regions, which varies as $\lambda^{-4}$ and hence one obtains stronger Rayleigh returns at UV. This allows us to infer temperatures using the analysis technique discussed in Hauchecorne and Chanin (1980). In this study, we have used the Rayleigh signal at $393 \mathrm{~nm}$ yielding temperature accuracies of $\sim 1-2 \mathrm{~K}$ in the stratospheric region. The receiver at Arecibo consists of a $0.8 \mathrm{~m}$ Cassegrain $\mathrm{f} / 15$ telescope. The backscattered photons are directed to a fiber having NA $\sim 0.35$ and a core diameter of $1.5 \mathrm{~mm}$. A use of a narrow bandwidth interference filter with FWHM $\sim 1 \mathrm{~nm}$ in front of a model R943-02 Hamamatsu photomultiplier tube reduces the background noise. The data were sampled at $0.25 \mu$ s using an EG\&G multichannel scaler/averager, providing a range resolution of $37.5 \mathrm{~m}$, which is further binned in altitude to give a final range resolution $600 \mathrm{~m}$.

The sounding of the atmosphere using Broadband Emission Radiometry (SABER) is a high precision instrument broadband radiometer which measures limb radiance emitted from the terrestrial atmosphere in 10 selected spectral bands ranging from 1.27 to $15 \mu \mathrm{m}$ onboard the Thermosphere Ionosphere Mesosphere Energetics and Dynamics (TIMED) satellite orbiting the earth's atmosphere at $74^{\circ}$ inclined plane. The temperature values are retrieved from SABER measurements of the atmospheric $15 \mu \mathrm{m} \mathrm{CO} 2 \operatorname{limb}$ emission. Utilized here are the 
SABER 1.07 data, which has good temperature accuracy with error in the order of $\pm 1.4 \mathrm{~K}$ in lower stratosphere, $\pm 1 \mathrm{~K}$ in middle stratosphere and $\pm 2 \mathrm{~K}$ in upper stratosphere and lower mesosphere (e.g., Remsberg et al., 2008).

High-resolution ground-based radiosonde balloons were launched almost regularly over Gadanki $\left(13.5^{\circ} \mathrm{N}\right.$, 79. $2^{\circ} \mathrm{E}$ ) since 19 April 2006. Most of these radiosondes were launched around $1200 \mathrm{UT}$ (LT= UT+5:30hrs). All the atmospheric parameters were collected with a height resolution of $10 \mathrm{~m}$ (sampled at 2-s intervals). Later, the entire data set has been interpolated to $100 \mathrm{~m}$ so as to remove outliers arising from random motions of the balloon. A detailed discussion on radiosonde technique are provided elsewhere (e.g., Basha and Ratnam, 2009).

For the present study we make use of the measurements between 30 and $55 \mathrm{~km}$ from both the above mentioned lidar systems where a high accuracy in the temperature estimates $(\sim 0.5-1.5 \mathrm{~K})$ are ideal for measurements of short period gravity wave features.

\section{Results and Discussion}

As described earlier in Figure 1 that the convective regions of near similar nature were located very near to the Gadanki latitudes compared to the Arecibo. To investigate the effects of such a difference, it is important to know whether the background thermo-dynamical conditions at both the locations were near similar. To verify this, Figure 2 plots the observed nightly mean temperature profiles for Gadanki (top panel) and Arecibo (bottom panel) and their comparison with measurements from the Sounding of the Atmosphere using Broadband Emission Radiometry (SABER) instrument aboard the Thermosphere-Ionosphere-Mesosphere Energetics and Dynamics (TIMED) satellite (Mertens et al., 2004). The SABER data were selected when the data were available within a $5^{\circ} \times 5^{\circ}$ latitude-longitude grid surrounding Gadanki and Arecibo for a comparison with temperature estimates made with ground based lidars. It should be noted that owing to the temporal and spatial coincidence between lidar and overhead SABER passes, only one night (07 December 2009) of direct comparison could be made. We used an average profile obtained from the temperature profiles obtained in the above mentioned grid (please note that for both the locations, the average difference of satellite pass is $\sim 2^{\circ}$ ). We note a broad similarity in the temperature profiles at both the locations. At both places, the temperature maximizes at around 40-45 km and then starts decreasing above and below this height range, which is consistent with the location of the stratopause. The altitude of stratopause at these low-latitude locations appear to be slightly lower than those observed at mid-latitude locations, which occurs around $48 \mathrm{~km}$ at $54^{\circ} \mathrm{N}$ (Gerding et al., 2008). Also noteworthy is that the space-borne SABER temperature retrievals have reasonable agreement (within $1 \sigma$ deviation) with ground based lidar deduced temperature measurements. The differences, whatever small, are possibly because of the differences in the spatial location of measurements and time of the satellite measurements. Overall, a somewhat similar background thermal structure emphasizes that the mean thermal structure at both the places are more-or-less similar (at least during 7-10 December 2009) making it reasonable to compare the variability.

Figure 3 shows the observed temperature variability at both the locations for the lidar operations on the nights of 07, 09 and 10 December, 2009. Each profile shows a 10 min average and each successive profile is shifted by 20 $\mathrm{K}$ while the duration of observation is mentioned in the figure headings. The left panels plot the temperature and vertical wavelength spectra for Gadanki while the right panels plot the corresponding data over Arecibo. In Figure 3A are the 10 minutes averages of the temperature data collected over Gadanki for 07 December 2009. One notices the temperature perturbations with their phase signatures descending with time, which is indicative of a gravity wave propagating upward. One also may note a large variability in the thermal structures at both Gadanki and Arecibo. However, one also notices that in general the variability is significantly larger over Gadanki compared with Arecibo. Such differences should be associated with the source regions of the waves. Figure 3B plots the vertical wavelength spectra for the corresponding nights. Horizontal dashed lines in each plot show $90 \%$ confidence levels. One can note the large amplitude of the $\sim 8$ to $20 \mathrm{~km}$ vertical wavelengths in the data (we ignore periodicity $>20 \mathrm{~km}$ because of available data length). Similarly, the variability observed on 09 December 2009 are plotted in Figure 3C and 3D, while Figure 3E, F plot the temperature variability observed on 10 December 2009.

To compare the nature of short period variability in the middle atmospheric temperatures, a Lomb-Scargle periodogram analysis was carried out for both Gadanki and Arecibo lidar temperature data. For better estimates of short period wave amplitudes, prior to carrying out the spectral analysis the following analysis was performed: a) the temperature data were averaged for $5 \mathrm{~km}$ altitude bins for altitudes 35 to $55 \mathrm{~km}$, and b) a running average trend (of $3 \mathrm{hr}$ ) was removed from the data. Figure 4A shows the results of the Lomb-Scargle periodogram analysis for Gadanki (left panels) and Arecibo (right panels) for 07 December 2009. The horizontal dashed lines in each plot show the $90 \%$ confidence levels. One may note that at both the places, $30 \mathrm{~min}$ to $2 \mathrm{hr}$ waves 
dominate the short period wave spectra. Large amplitudes of $30 \mathrm{~min}$ to $1 \mathrm{hr}$ waves are clearly noted at both the locations. One may see that the $0.6 \mathrm{hr}$ wave has large amplitudes over Gadanki throughout the altitude regions in comparison to the amplitudes observed over Arecibo. Also noteworthy is the amplitude growth for waves at both the locations. The 1-2 hr wave spectra show that some of the waves were propagating with increasing amplitudes from the 30 to $55 \mathrm{~km}$ altitude regions at both the places. In particular, over Arecibo, a $2.1 \mathrm{hr}$ wave is observed to be growing consistently in amplitude while, the shorter period waves were irregular in their amplitude growth. The Gadanki data on the other hand, show that shorter period wave amplitudes were growing significantly (in particular, the $\sim 0.6$ and $1.2 \mathrm{hr}$ waves), while irregular wave growth is noted for 1.5-2.5 hr waves during their propagation from 30 to $55 \mathrm{~km}$ altitudes. Figure 4B and 4C show the dominant wave periods for the observations carried out on 09 and 10 December 2009. On 09 December one can see a strong growth in wave amplitudes over Gadanki compared with Arecibo, particularly for the $\sim 0.6$ and $1.2 \mathrm{hr}$ waves, while the $\sim 1.0 \mathrm{hr}$ wave exhibits strong growth in its amplitude over Arecibo. As noted on the earlier night of observations, the 1.5-2.5 hr waves show irregular wave growths at both the locations. The 10 December 2009 data exhibit a somewhat different nature of its spectrum compared with the earlier nights. The Gadanki wave spectrum show a bunching of waves at $0.5-1.0 \mathrm{hr}$ periods, while Arecibo data show a spectrum that is well distributed from $0.5-2.5 \mathrm{hr}$, which is similar to the earlier nights. The wave growth aspect shows short period $(\sim 0.6 \mathrm{hr})$ waves to grow in amplitude over Gadanki while a comparatively larger period $(\sim 1.55 \mathrm{hr})$ wave grew in amplitude over Arecibo.

Though it is clear that over Gadanki some of the short period gravity waves exhibited significantly higher amplitudes compared with Arecibo, for a better comparison on the energy input of the waves of the middle atmosphere, we calculate the potential energy for short period waves $(<2.0 \mathrm{hr}$ wave period). The method opted for the calculation of potential energy is similar to those followed widely by Wilson et al. (1991). Figure 5 plots the results of these calculations. We note that the potential energies of the waves are significantly higher over Gadanki compared with Arecibo. In particular, above $40 \mathrm{~km}$, the Gadanki data show the potential energy of the short period waves to be at least double the values noted over Arecibo for all three nights. In general, the measurements of potential energies and their simultaneous comparison over two different low latitude stations are nonexistent to best of our knowledge. The potential energy estimates are comparable to the earlier reported values at individual low (Sivakumar et al., 2006) and mid latitude stations (Wilson et al., 1991). For example, our observations reveal the potential energies for $30-40 \mathrm{~km}, 40-50 \mathrm{~km}$, and $50-55 \mathrm{~km}$ over Gadanki to be in the range of $\sim 2.6-14.8 \mathrm{~J} / \mathrm{kg}, \sim 1.6-29.8 \mathrm{~J} / \mathrm{kg}$, and $\sim 9.4-36.2 \mathrm{~J} / \mathrm{kg}$ and correspondingly, $\sim 0.3-4.8 \mathrm{~J} / \mathrm{kg}, \sim 0.4-9.7 \mathrm{~J} / \mathrm{kg}$, and $\sim 2.1-18.6 \mathrm{~J} / \mathrm{kg}$ over Arecibo, respectively. These values compare well with the values reported by Wilson $e t$ al (1991), where potential energies were found to be $\sim 6-13 \mathrm{~J} / \mathrm{kg}$ for altitudes $30-45 \mathrm{~km}$ and $\sim 16-30 \mathrm{~J} / \mathrm{kg}$ for altitudes $45-60 \mathrm{~km}$ for observations carried out at Haute Provence $\left(44^{\circ} \mathrm{N}, 6^{\circ} \mathrm{E}\right)$ and Biscarosse (BIS) $\left(44^{\circ} \mathrm{N}, 1^{\circ} \mathrm{W}\right)$. In an earlier study over Gadanki, Sivakumar et al. (2006) reported the potential energy to be in the range of 0.1 $10 \mathrm{~J} / \mathrm{kg}$ at $30-40 \mathrm{~km}$ altitudes and $\sim 10-30 \mathrm{~J} / \mathrm{kg}$ at $40-50 \mathrm{~km}$ altitudes, which also is in good agreement with our values, especially at the upper limits of the considered interval. It is worth mentioning here that the calculated potential energies over Gadanki are larger than Arecibo which is consistent with the observed larger variability over Gadanki compared with Arecibo.

Further, to identify the cause of similar wave periods but with lesser amplitudes we inspect the source strength (OLR) and wind features over both the locations. Regarding the source, owing to the numerous evidence that convective regions at lower atmosphere generate gravity waves spectrum that has similar wave periods, we look at Figure 1, where one notes clear signatures of convective patches related to the ITCZ during $7-10$ December 2009 at locations nearby our observations. In particular, the OLR data reveal stronger convection patterns very close to Gadanki's latitude. This suggests that gravity wave sources for both locations are of a convective nature and also related to the ITCZ's associated convection movements. In particular, the OLR data suggests strong convection and hence more wave energy over Gadanki. To ascertain that winds had an insignificant role in the observed wave features, Figure 6 plots the radiosonde zonal (left panels) and meridional (right panels) wind profiles for all these nights observed at 1200 GMT for both locations. The zonal winds at both the locations show nearly identical variability while there is a little difference in the meridional winds. Over Gadanki and Arecibo the zonal component shows eastward wind amplitudes consistently to be $\sim 5-15 \mathrm{~m} / \mathrm{s}$ with a maximum around 10-12 km during 07-10 December 2009. On the other hand, the meridional winds over Gadanki show a northward flow with a peak velocity of $15 \mathrm{~m} / \mathrm{s}$ around $10 \mathrm{~km}$, which are somewhat different with that observed over Arecibo at similar altitudes. One may note that observed shears are not more than $5 \mathrm{~m} \mathrm{~s}^{-1} \mathrm{~km}^{-1}$ at any given altitude region of $0-35 \mathrm{~km}$, and as it is the shears that are important for the wave filtering by winds, the observed differences are not significant. Our finding that the differences observed in wave amplitudes and wave periodicity noted in our data supports the earlier observed gravity wave features and wave sources by Ziang et al 
$(2003,2005)$, where they mentioned that when westward winds are $<20 \mathrm{~m} / \mathrm{s}$, then convectively generated waves are dominant in the middle atmosphere.

A similar upward propagating wave measured over both locations strongly suggests a somewhat similar wave sources, i.e. the convective cells. Further, a similar zonal wind field at both locations suggests that it is not the wind filtering or the wind shears that are the cause of the observed differences in the wave energy at Gadanki and Arecibo. The only difference is that a strong convection pattern (associated with ITCZ movement), which was noted very close to the Gadanki while no such pattern was noted nearby Arecibo. It is also understood that tropospheric convection is one of the dominant source of gravity waves with a spectrum varying from 15 min to 2 hours (Vadas and Liu, 2009). Therefore, our results suggest that though the nature of sources over both locations may be the same (i.e., convection), a close proximity of a strong convection pattern was the reason for the observed higher potential energy (and amplitudes) of short period waves over Gadanki compared with Arecibo. Though strong shears of the background wind will effect the propagation of different waves upwards (e.g., Lindzen, 1981), it does not seem to have any role in the present case, as the background zonal mean wind structure is more or less similar at both locations.

\section{Concluding Remarks}

The results of the present investigation can be summarized as following:

a) The observed short-period variability at Gadanki $\left(13.5^{\circ} \mathrm{N}, 79.2^{\circ} \mathrm{E}\right)$ and Arecibo $\left(18.3^{\circ} \mathrm{N}, 66.7^{\circ} \mathrm{W}\right)$ show a similarity in the periodicity, which emphasizes a somewhat similar nature of gravity wave sources.

b) The short-period wave amplitudes over Gadanki are larger compared with the observed amplitudes over Arecibo.

c) The zonal, as well as the meridional winds observed with radiosonde at both locations show insignificant shears with regard to the observed differences in wave amplitudes (and the potential energy) noted in lidar deduced temperature data at both stations.

These case studies represent a unique data set to investigate the characteristics of observed short period waves over Gadanki and Arecibo, both representing tropical low-latitude sites. It is noted that the amplitudes and associated potential energies of short period waves are significantly larger over Gadanki compared with Arecibo. It is noted that the wind shears at both the locations did not reveal any significant changes. Further absence of any variable wave sources, suggests that the observed differences to be associated with the stronger and closer convective patterns in the case of Gadanki. Such simultaneous data sets from two tropical locations demostrate the coupling between the lower and the middle atmosphere.

\section{Acknowledgements}

This work is supported by Department of Space, Govt. of India. The efforts of Mr. K. Raghunath and his team for NARL lidar operations are duly acknowledged. The Arecibo Observatory is operated by SRI International under a cooperative agreement with the NSF (AST-1100968), and in alliance with Ana G. Méndez-Universidad Metropolitana, and the Universities Space Research Association.

\section{References}

Basha, G. \& Ratnam, M. V. (2009). Identification of atmospheric boundary layer height over a tropical station using high-resolution radiosonde refractivity profiles: Comparison with GPS radio occultation measurements. $J$. Geophys. Res., 114, D16101. http://dx.doi.org/10.1029/2008JD011692

Espy, P. J. \& Huppi, R. (1997). The intertropical convergence zone as a source of short-period mesospheric gravity waes near the equator. J. Atmos. Sol. Terr. Phys., 59(13), 1665-1671. http://dx.doi.org/10.1016/S1364-6826(96)00165-4

Chanin, M. L. \& Hauchecorne, A. (1984). Lidar studies of temperature and density using Rayleigh scattering. 'Handbook for MAP', ed. by R. A. Vincent, 13, 87-99.

Fritts, D. C. \& Alexander, M. J. (2003). Gravity wave dynamics and effects in the middle atmosphere. Rev. Geophys., 41. http://dx.doi.org/10.1029/2001RG000106

Gerding M. J., Höffner, J., Lautenbach, M., et al. (2008). Seasonal variation of temperatures between 1 and 105 $\mathrm{km}$ altitude at $54^{\circ} \mathrm{N}$ observed by lidar. Atmos. Chem. Phys., 8, 16175-16218. http://dx.doi.org/10.5194/acpd-8-16175-2008

Hauchecorne, A. \& Chanin, M. L. (1980). Density and temperature profiles obtained by lidar between 35 and 70 km. Geophys. Res. Lett., 7, 565-568. http://dx.doi.org/10.1029/GL007i008p00565 
Jiang, J. H., Wang, B., Goya, K., et al. (2004). Geographical distribution and interseasonal variability of tropical deep convection: UARS MLS observations and analyses. J. Geophys. Res., 109, D03111. http://dx.doi.org/10.1029/2003JD003756

Jiang, J. H., Eckermann, S. D., Wu, D. L., et al. (2005). Seasonal variation of gravity wave sources from satellite observation. J. Atmos. Space. Res., 35, 1925-1932. http://dx.doi.org/10.1016/j.asr.2005.01.099

Lane, T. P., Sharman, R. D., Clark, T. L., et al. (2003). An Investigation of turbulence generation mechanisms

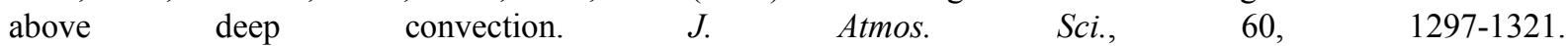
http://dx.doi.org/10.1175/1520-0469(2003)60<1297:AIOTGM>2.0.CO;2

Lindzen, R. S. (1981). Turbulence and stress owing to gravity wave and tidal breakdown. J. Geophys. Res., 86, 9707-9714. http://dx.doi.org/10.1029/JC086iC10p09707

Martens, C. J., Schmidlin, F. J., Goldberg, R. A., et al. (2004). SABER observations of mesospheric temperatures and comparisons with falling sphere measurements taken during the 2002 summer MaCWAVE campaign. Geophys. Res. Lett., 31, L03105. http://dx.doi.org/10.1029/2003GL018605

Raizada, S., Tepley, C. A., Janches, D., et al. (2004). Lidar observations of Ca and K metallic layers from Arecibo and comparison with micrometeor sporadic activity. J. Atmos. Sol. Terr. Phys., 66, 595-606. http://dx.doi.org/10.1016/j.jastp.2004.01.030

Raizada, S., Tepley, C. A., Aponte, N. et al. (2011). Characteristics of neutral calcium and $\mathrm{Ca}^{+}$near the mesopause, and their relationship with sporadic ion/electron layers at Arecibo. Geophys. Res. Lett., 38, L09103. http://dx.doi.org/10.1029/2011GL047327

Remsberg, E. E. et al. (2008). Assessment of the quality of the Version 1.07 temperature-versus-pressure profiles in the middle atmosphere from TIMED/SABER. J. Geophys. Res., 113, D17101.

Sharma, S., Sivakumar, V., Bencherif, H., et al. (2006). A comprehensive study on middle atmospheric thermal structure over a tropic and sub-tropic stations. J. Adv. Space Res., 37(12), 2278-2283. http://dx.doi.org/10.1016/j.asr.2005.09.003

Sivakumar, V., Rao, P. B., \& Bencherif, H. (2006). Lidar observations of middle atmospheric gravity wave activity over a low-latitude site (Gadanki, 13.5 N, 79.2 E). Ann. Geophys., 24, 823-834. http://dx.doi.org/10.5194/angeo-24-823-2006

Tepley, C. A., Raizada, S., Zhou, Q., et al. (2003). First simultaneous observations of $\mathrm{Ca}^{+}, \mathrm{K}$, and electron density using lidar and incoherent scatter radar at Arecibo. Geophys. Res. Lett. 30(1), 1009. http://dx.doi.org/10.1029/2002GL015927

Vadas, S. L., \& Liu, H. L. (2009). Generation of large-scale gravity waves and neutral winds in the thermosphere from the dissipation of convectively generated gravity waves. J. Geophys. Res., 114. A10310. http://dx.doi.org/10.1029/2009JA014108

Vadas, S. L., Yue, J., She, C. Y., et al. (2009). A model study of the effects of winds on concentric rings of gravity waves from a convective plume near Fort Collins on 11 May 2004. J. Geophys. Res., 114, D06103. http://dx.doi.org/10.1029/2008JD010753

Wilson, R., Chanin, M. L., \& Hauchecorne, A. (1991). Gravity waves in the middle atmosphere observed by Rayleigh lidar 1. Case studies. J. Geophys. Res., 96(D3), 5153-5167. http://dx.doi.org/10.1029/90JD02231

Wrasse, C. M., Nakamura, T., Takahashi, H., et al. (2006). Mesospheric gravity waves observed near equatorial and low-middle latitude stations: wave characteristics and reverse ray tracing results. Ann. Geophys., 24, 3229-3240. http://dx.doi.org/10.5194/angeo-24-3229-2006

Zhou Q, H., Monroy, H., Fritts, D. C., et al. (2000). Radar observations of longitudinal variability of tidal/planetary waves and mean motions in the tropical mesosphere. J. Geophys. Res., 105, 2151-2162. http://dx.doi.org/10.1029/1999JD901083 

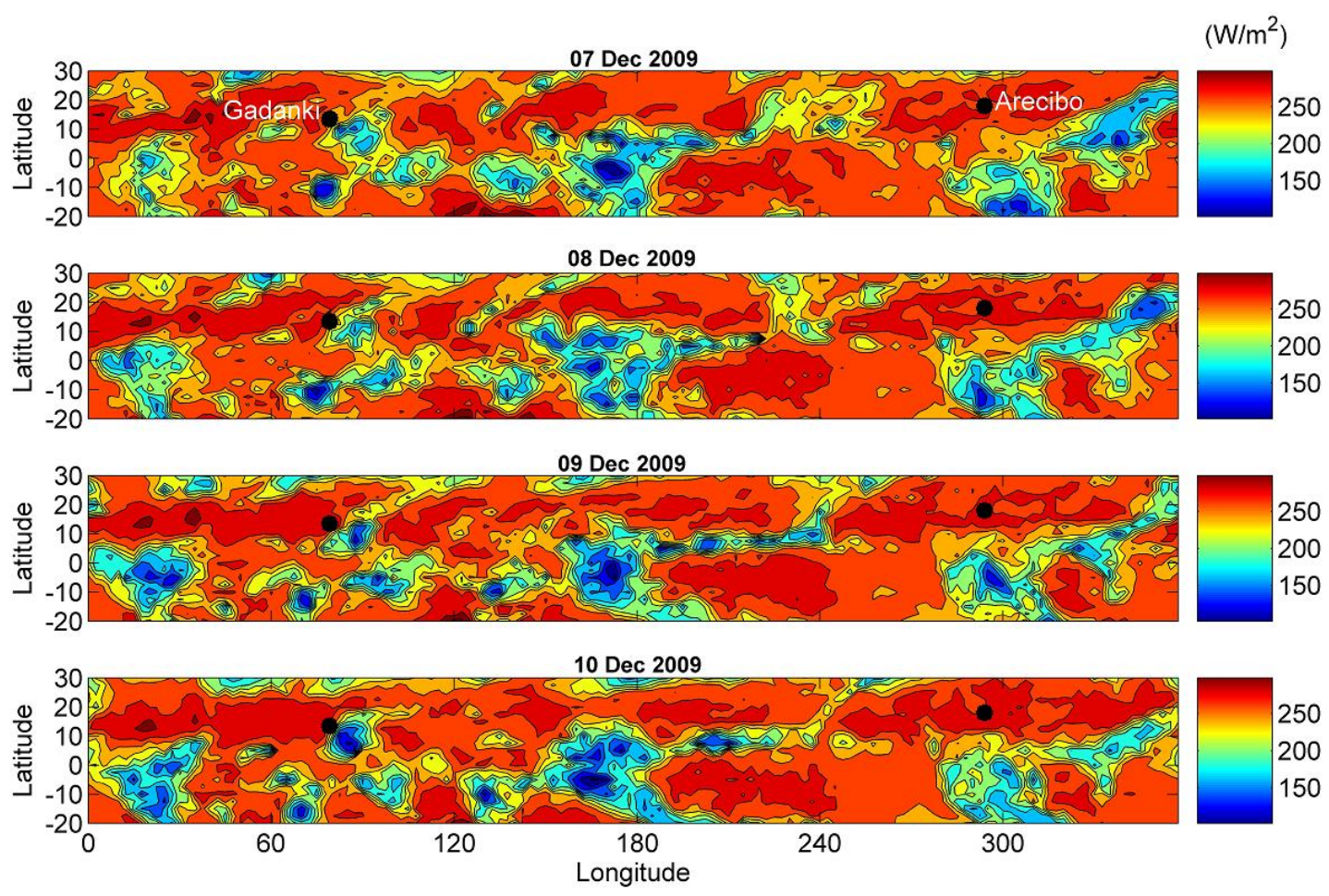

Figure 1. Latitude-longitude variation of OLR observed during 07 - 10 December 2009.

Dark black spots in each plot show the position of Gadanki and Arecibo 

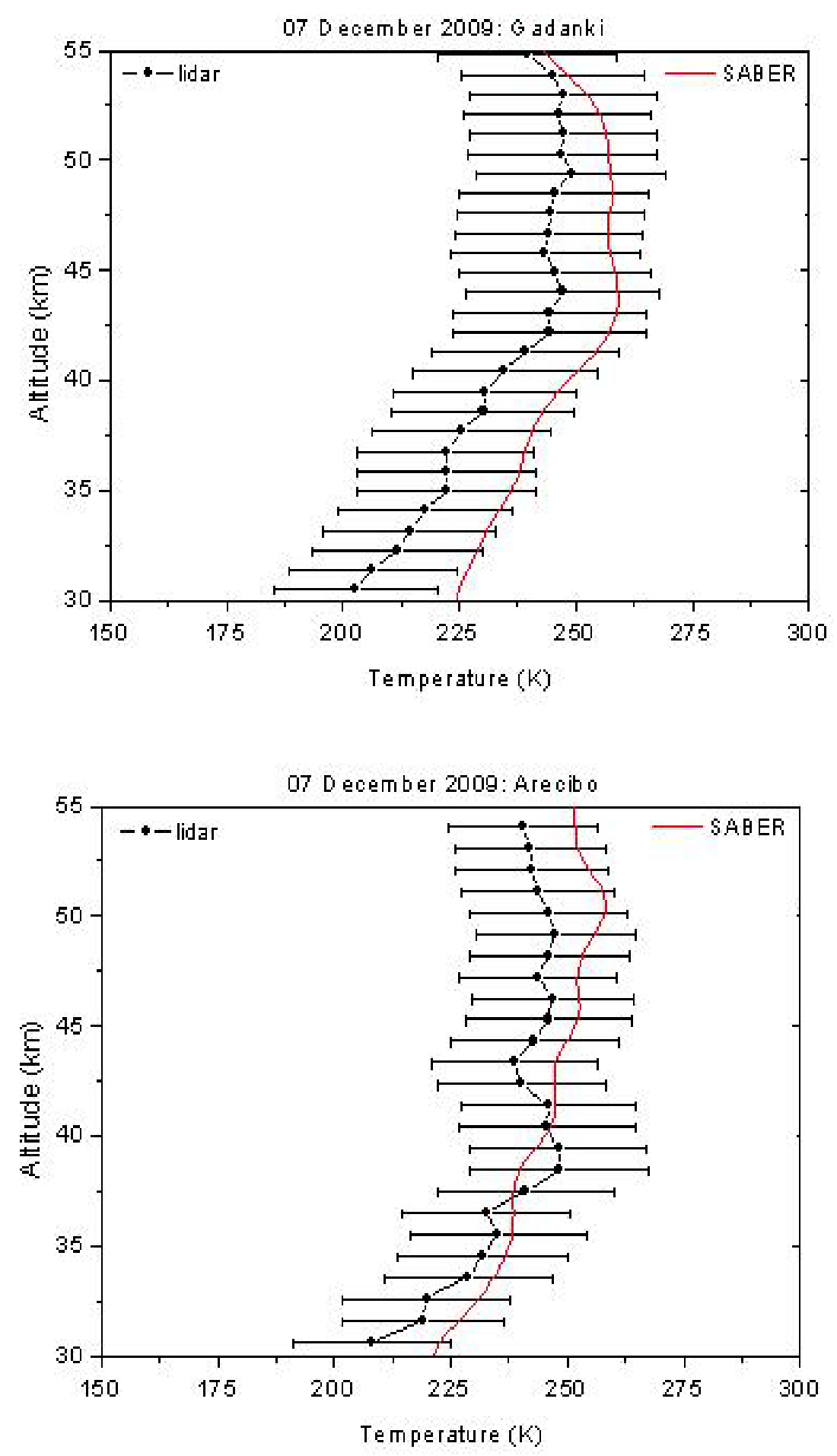

Figure 2. Comparison of nightly mean lidar temperatures and SABER temperatures on board the TIMED satellite. Horizontal bars on the lidar temperature profile show the standard deviation obtained while averaging over that night (07 Dec. 2009) 

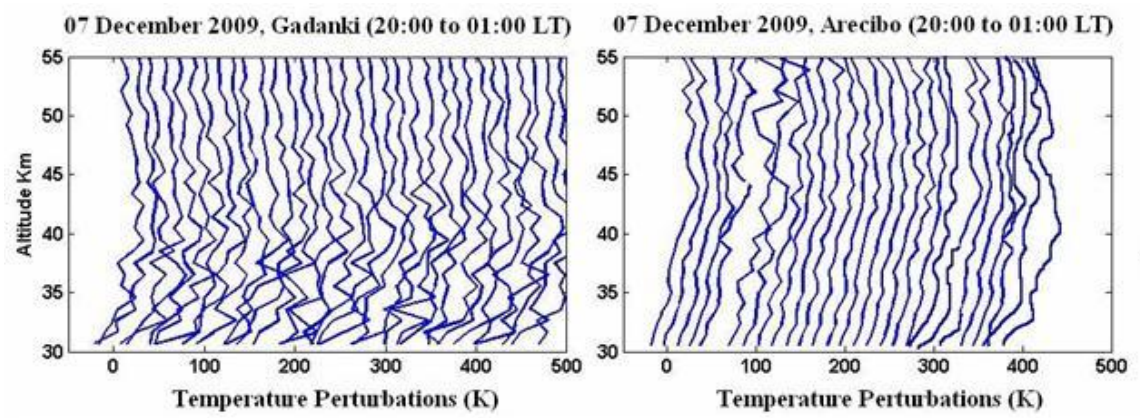

A
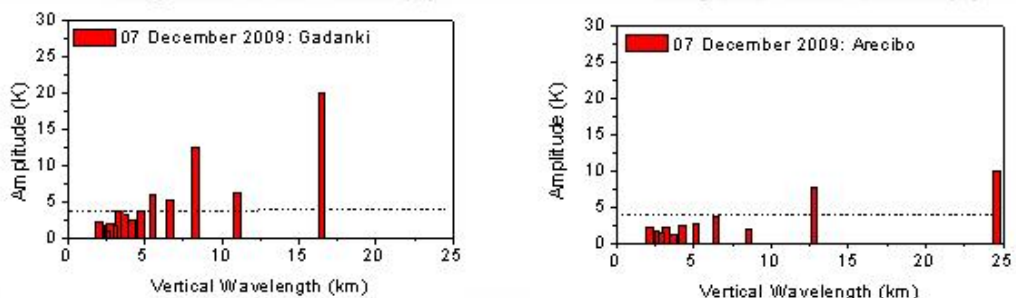

B

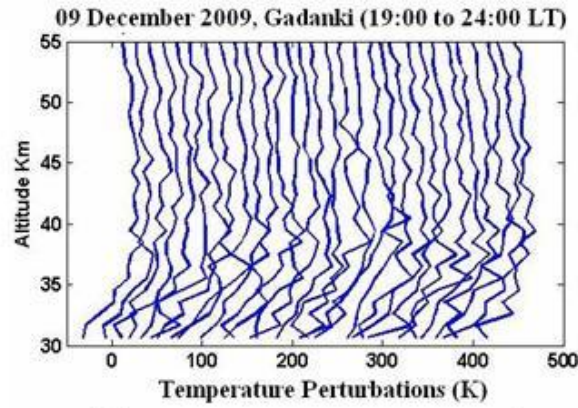

09 December 2009, Arecibo (20:00 to 01:00 LT)
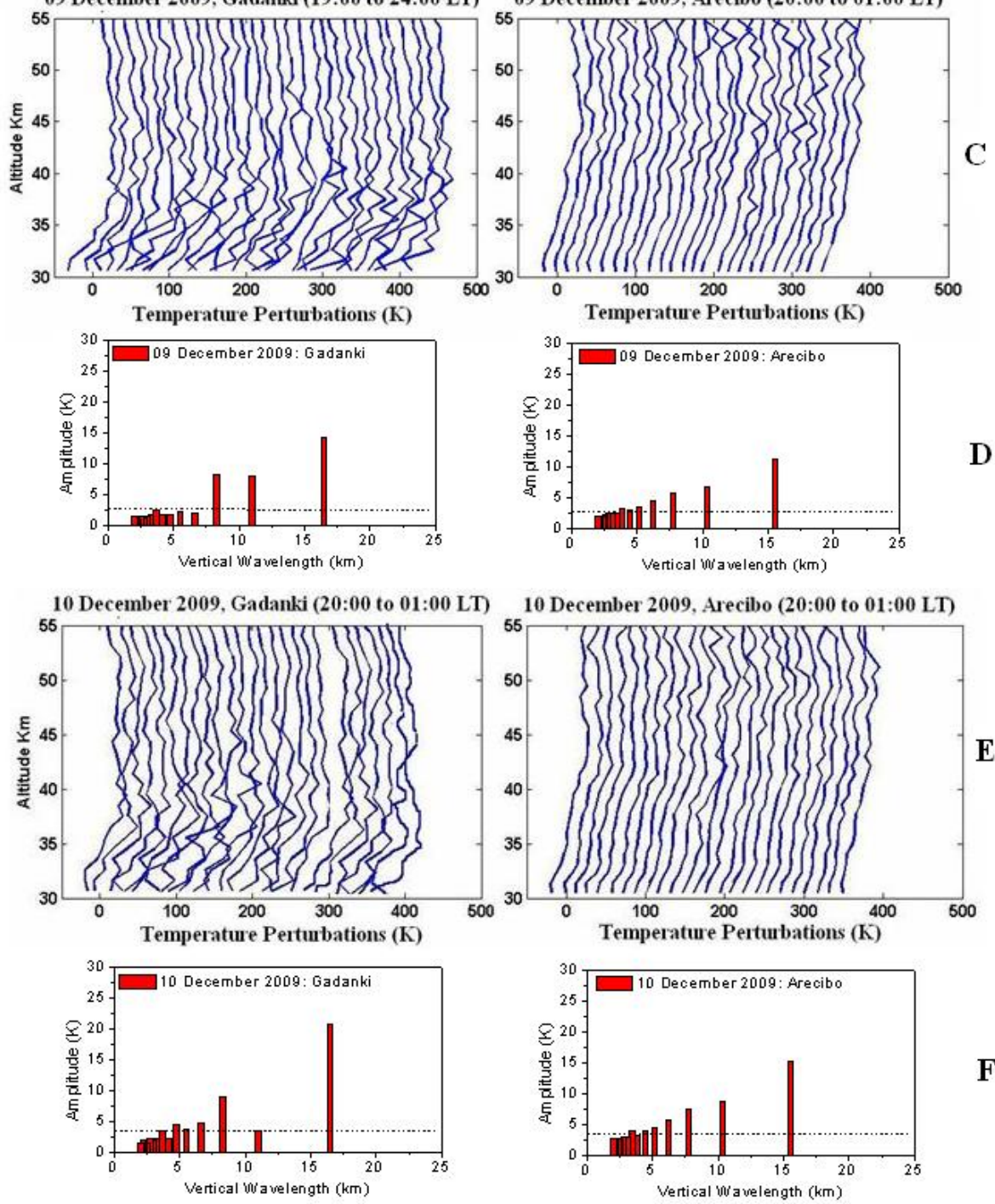

$\mathbf{F}$

Figure 3. Middle atmospheric thermal structure variability over Gadanki (left panels) and Arecibo (right panels) for 07 (A), 09 (C) and 10 (E) December 2009 together with their vertical wavelength spectra (B, D, F). The horizontal dashed lines in each plot of B, D, F show $90 \%$ confidence levels 

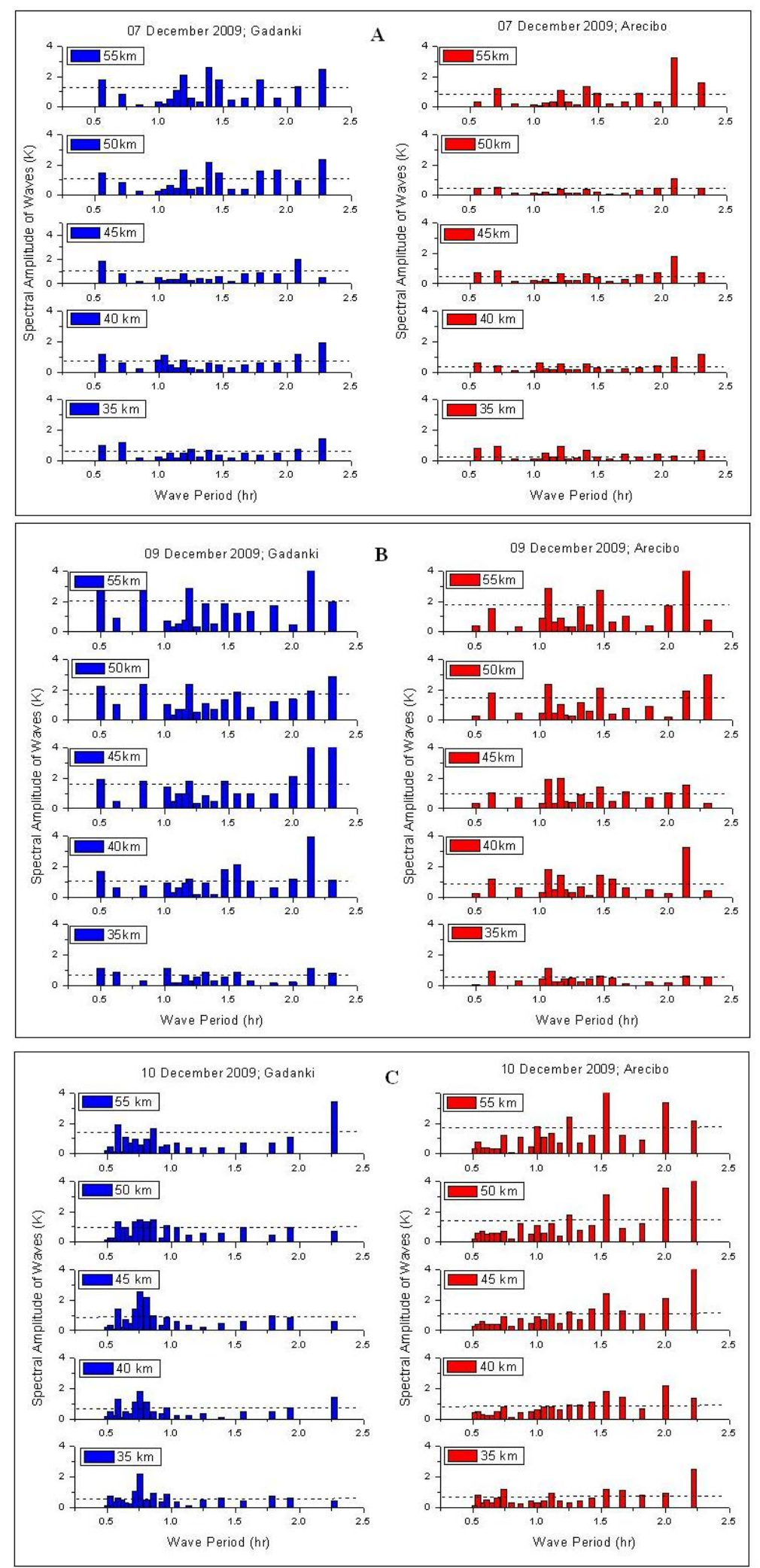

Figure 4. The Lomb-Scargle periodogram analysis for a $5 \mathrm{~km}$ altitudinal average from $35-55 \mathrm{~km}$ range for (A)

07 December (B) 09 December and (C) 10 December, 2009. Note the large amplitudes of short period oscillations over Gadanki (left) compared with Arecibo (right). The horizontal dashed lines in each plot of B, D, F show $90 \%$ confidence levels 


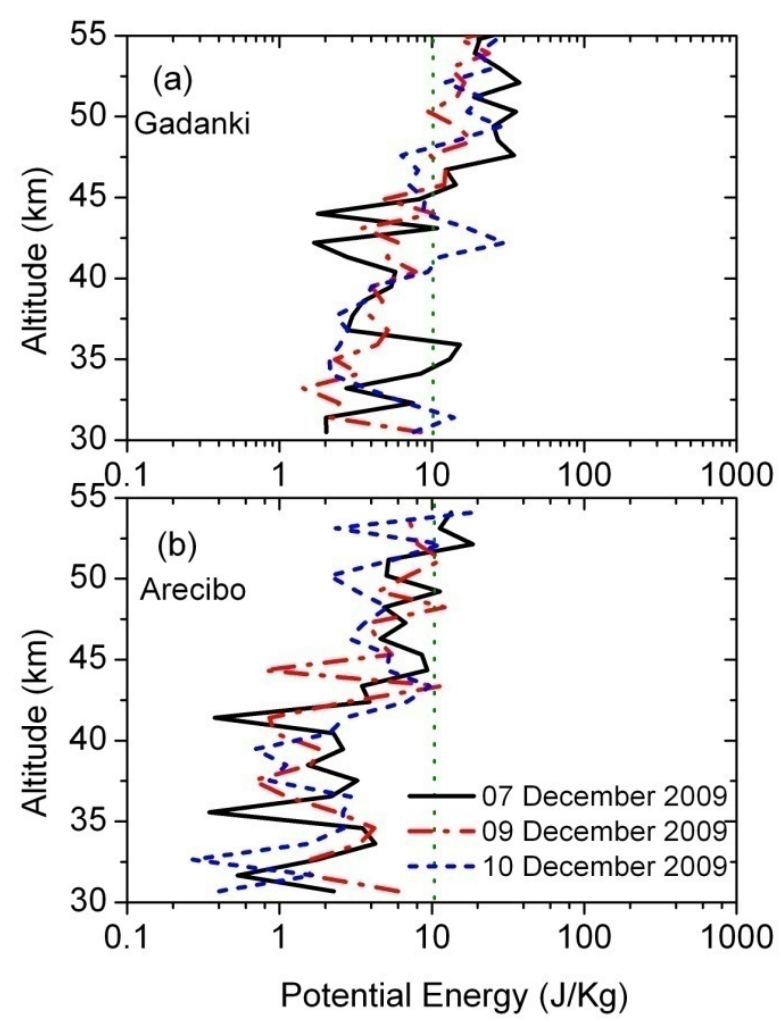

Figure 5. Variability in the potential energy of short period waves ( $<2 \mathrm{hr}$ periodicity) over Gadanki (top panel) and Arecibo (bottom panel). Note the larger potential energy over Gadanki than for Arecibo

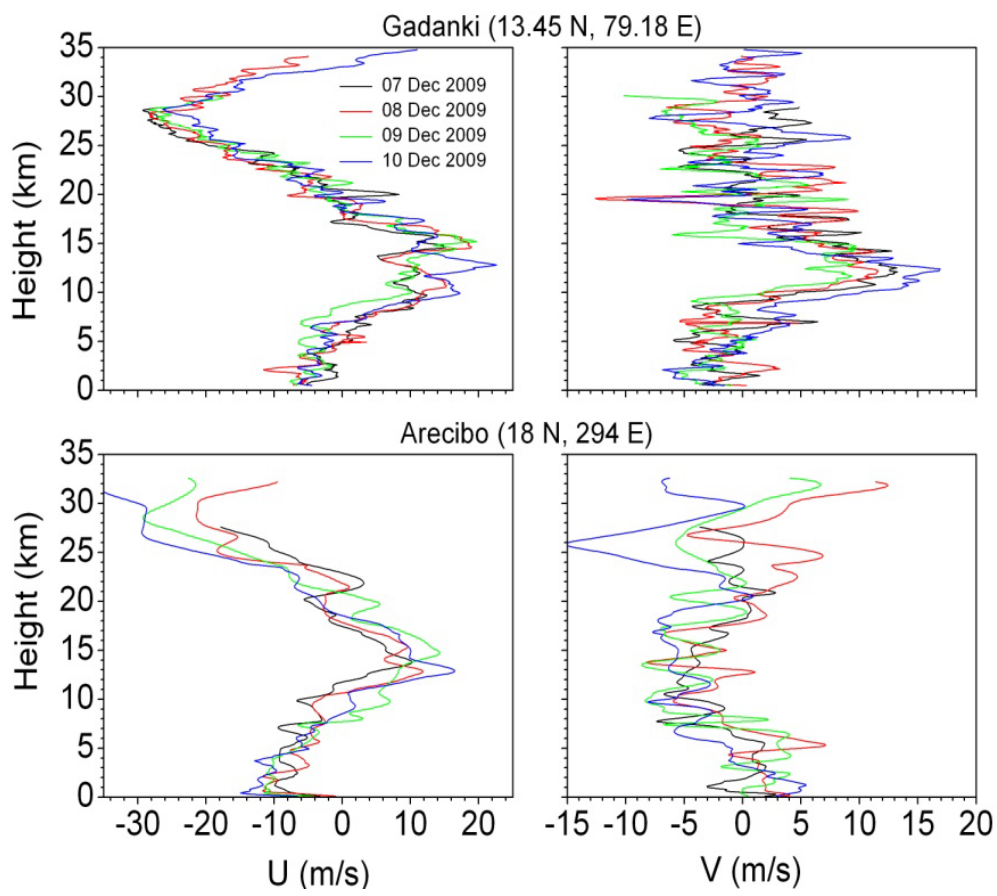

Figure 6. Radiosonde measurements of the zonal (left panel) and meridional (right panel) wind variability at 12 GMT over Gadanki (top) and Arecibo (bottom) 